\title{
Long term use of curcumin in two smoldering multiple myeloma patients
}

\author{
Terry Golombick ${ }^{1}$, Terrence H. Diamond ${ }^{1}$, Arumugam Manoharan ${ }^{2}$, Rajeev Ramakrishna ${ }^{2}$ \\ 1. Department of Endocrinology, St George Hospital, Sydney, Australia. 2. Southern Sydney Haematology, University of \\ Wollongong, NSW, Australia.
}

Correspondence: Terry Golombick. Address: Prichard Wing, St George Hospital, Kogarah, NSW, Australia, 2217. Email: terry.golombick@sesiahs.health.nsw.gov.au

Received: November 13, 2012

Accepted: January 24, 2013

Online Published: February 18, 2013

DOI : $10.5430 / \mathrm{jhm} . \mathrm{v3n} 1 \mathrm{p} 18$

URL: http://dx.doi.org/10.5430/jhm.v3n1p18

\section{Abstract}

Introduction: Smoldering Multiple Myeloma (SMM) is an asymptomatic plasma cell disorder which has an overall risk of progression to multiple myeloma of $10 \%$ per year. The cornerstone of managing SMM is a "watch and wait" strategy. Curcumin has been shown to improve disease status in some patients with MGUS and SMM and has been added to the mainstream treatment of myeloma patients. We report here for the first time on long term use of oral curcumin in 2 SMM patients.

Patients: Two male Caucasian patients over the age of 40 presented to their general practitioners with fatigue/shoulder pain. Blood tests revealed paraproteinemia and a diagnosis of SMM was made based on IMWG guidelines. Both were entered into a 9 month clinical trial of oral curcumin in patients with plasma cell dyscrasias. Thereafter, they elected to continue on the same regimen of oral curcumin, for a period of 2 years.

Results/Discussion: Both patients showed continued improvement in a number of markers of disease activity including serum free light chains, paraprotein and \% plasma cells in the bone marrow. These results suggest that patients with smoldering myeloma may benefit from daily ingestion of curcumin and long term use does not result in toxicity.

\section{Key words}

Smoldering Multiple Myeloma, Monoclonal Gammopathy of Undetermined Significance, Curcumin

\section{Introduction}

Smoldering Multiple Myeloma (SMM) is an asymptomatic plasma cell disorder which has an overall risk of progression to multiple myeloma of $10 \%$ per year for the first 5 years. This diminishes gradually thereafter. SMM is a more advanced pre-malignant condition than monoclonal gammopathy of undetermined significance (MGUS).The cornerstone of managing SMM is a "watch and wait" strategy ${ }^{[1]}$. Although it is currently not possible to predict the clinical course of SMM, features predicting patients at highest risk include the size and type of M-protein, with IgA having a higher risk compared to IgG paraprotein, \% plasma cell dyscrasia, and an abnormal serum-free light chain ratio. 
Given the uncertainty of disease progression with SMM, early intervention aimed at reducing the abnormal protein load, the abnormal serum-free light chain ratio and the \% plasma cell load would be of benefit to the patient. It would be essential that this preventative approach does not itself increase the risk of progression or result in toxicity. Curcuma longa (turmeric) is a perennial herb belonging to the ginger family. The most active component in turmeric is curcumin ${ }^{[2]}$. Based on its demonstrated anti-myeloma cell activity, both in vitro and in vivo ${ }^{[3,4]}$, we have carried out both a 6 month pilot study ${ }^{[5]}$ and a 6 month randomised, double-blind placebo-controlled cross-over $4 \mathrm{~g}$ study and a 3 month open-label $8 \mathrm{~g}$ extension study ${ }^{[6]}$ and shown that oral curcumin can, in a select group of MGUS and SMM patients, decrease free light chains ( $\mathrm{rFLC}, \mathrm{dFLC}$ and iFLC), paraprotein and bone resorption. Here, we present a report of two patients with SMM who were recruited into our second study ${ }^{[6]}$ and who elected to continue on the same regimen of oral curcumin daily after the study.

\section{Case presentations}

Patient 1: A 47 year old male presented to his GP in 2010 with a 3 month history of fatigue. Routine blood tests showed an IgG kappa paraprotein of $29.7 \mathrm{~g} / \mathrm{L}, 33 \%$ plasma cells in the bone marrow and a free light chain ratio (rFLC) of $26.77(\mathrm{~K}=$ $97.7 \mathrm{mg} / \mathrm{L} ; \mathrm{L}=3.65 \mathrm{mg} / \mathrm{L}$ ). Renal function and calcium levels were normal.

Patient 2: A 66 year old male whose disease was diagnosed in 2010 because of an unusual acromio-clavicular septic arthritis. Blood tests revealed an IgG lambda paraprotein of $31.7 \mathrm{~g} / \mathrm{L}, 7 \%$ plasma cells in the bone marrow and $\mathrm{rFLC}$ of 0.3 $(\mathrm{K}=15.7 \mathrm{mg} / \mathrm{L} ; \mathrm{L}=53.2 \mathrm{mg} / \mathrm{L})$. Renal function and calcium levels were normal.

Table 1. Clinical data of patients 1 and 2 at baseline, 9 months and at 2 years of curcumin therapy

\begin{tabular}{|c|c|c|c|c|c|c|}
\hline Variable & 1. Baseline & 1.9 months & 1. 2 years & 2.Baseline & 2.9 months & 2.2 years \\
\hline age (years) & 47 & 48 & 49 & 66 & 67 & 68 \\
\hline$\%$ plasma cells & 33 & & 15 & 7 & & 2 \\
\hline Paraprotein $(\mathrm{g} / \mathrm{L})$ & 29.7 & 26.6 & 24.4 & 31.7 & 27.7 & 23.6 \\
\hline Free light chain ratio $(0.3-1.7)$ & 26.77 & 14.37 & 4.5 & 0.3 & 0.22 & 0.4 \\
\hline $\mathrm{dFLC}(\mathrm{mg} / \mathrm{L})$ & 94.1 & 137.7 & 125.4 & 37.5 & 37.9 & 46 \\
\hline $\mathrm{iFLC} \mathrm{(mg/L)}$ & 97.7 & 148 & 161 & 53.2 & 48.6 & 71.6 \\
\hline uiFLC & 3.65 & 10.3 & 35.6 & 15.7 & 10.7 & 25.6 \\
\hline Globulin $(22-38 \mathrm{~g} / \mathrm{L})$ & 47 & 40 & 39 & 53 & 48 & 51 \\
\hline Gamma globulin $(7-16 \mathrm{~g} / \mathrm{L})$ & 32.8 & 28.3 & 26.4 & 34.8 & 31.8 & 28.2 \\
\hline $\operatorname{Ig~G}(6.2-14.4 \mathrm{~g} / \mathrm{L})$ & 44.25 & 38.8 & 39.47 & 49.03 & 41.62 & 44.12 \\
\hline $\operatorname{Ig} \mathrm{M}(0.48-3.04 \mathrm{~g} / \mathrm{L})$ & 0.23 & 0.23 & 0.2 & 0.62 & 0.45 & 0.5 \\
\hline Ig A $(0.6-3.96 \mathrm{~g} / \mathrm{L})$ & 0.12 & 0.12 & 0.12 & 1.15 & 1.36 & 1.55 \\
\hline CD3 T cell $(\%)$ & 81 & 72 & 63 & 76 & 75 & 76 \\
\hline CD4 T helper cell (\%) & 48 & 41 & 30 & 40 & 44 & 47 \\
\hline CD8 cytotoxic T cell $(\%)$ & 29 & 26 & 26 & 29 & 27 & 31 \\
\hline Total protein $(64-83 \mathrm{~g} / \mathrm{L})$ & 95 & 84 & 84 & 92 & 86 & 84 \\
\hline 25-OH Vitamin D (nmol/L) & 153 & & & 158 & & \\
\hline
\end{tabular}

Based on the IMWG classification system, these two patients were diagnosed with SMM. They were entered into our 6 month randomised, double-blind placebo-controlled cross-over $4 \mathrm{~g}$ study and 3 month open-label $8 \mathrm{~g}$ extension study of oral curcumin. After 9 months of curcumin therapy, both patients demonstrated an improvement in paraprotein, rFLC, iFLC, uiFLC, total protein, as well as decreases in their elevated IgG, globulin and gamma globulin levels (see Table 1). Based on their overall clinical improvement, they elected to continue with curcumin therapy after completion of the clinical trial on a maintenance dose of $6 \mathrm{~g} / \mathrm{day}$. Follow up blood tests and a bone marrow biopsy were performed after 2 years of curcumin therapy in order to determine whether the curcumin had altered the disease progression. 
Results are shown in Table 1 and figures $1 \& 2$. Both patients had IgG paraproteinemia. They demonstrated a continued decrease in paraprotein, total protein, gamma globulin and IgG. There was also greater than $50 \%$ decrease in CD138+ plasma cells in their bone marrow. Patient 1 had a 33\% plasma cell count at baseline that decreased to $15 \%$ after 2 years of curcumin therapy (see figure $1 \mathrm{a} \& \mathrm{~b}$ ). Patient 2 had a $7 \%$ plasma cell count at baseline that decreased to $2 \%$ at the end of 2 years (see figure $2 \mathrm{a} \& \mathrm{~b}$ ). (Reviewed by two independent haematologists).

Figure 1a. Immunoperoxidase stain of CD138 plasma cells in bone marrow of Patient 1 at baseline (33\%)

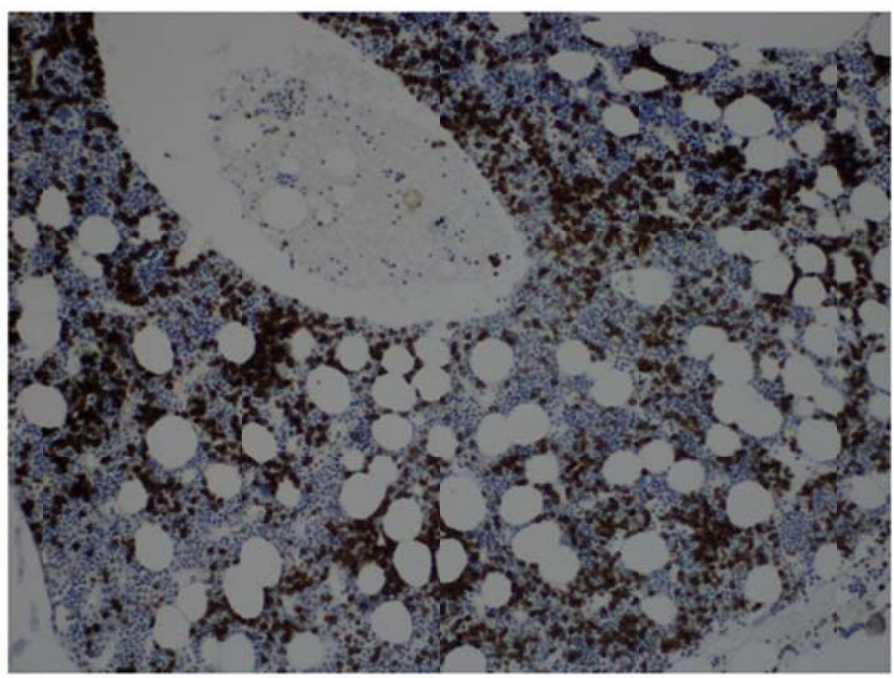

Figure 1b. Immunoperoxidase stain of CD138 plasma cells in bone marrow of Patient 1 after 2 years of curcumin therapy $(15 \%)$

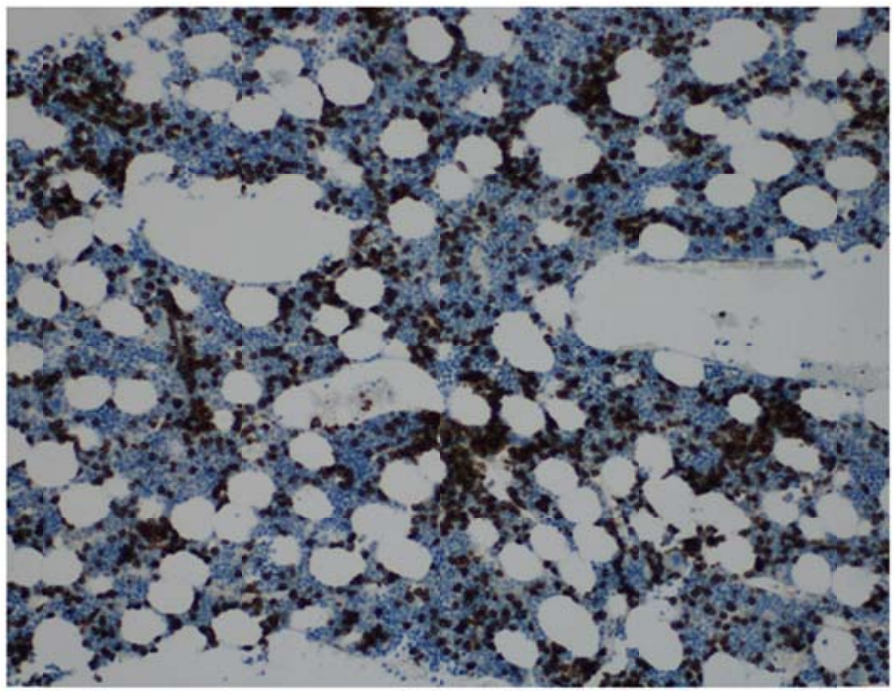

Table 1 shows that the free light chain ratio decreased from 26.8 to 4.5 in Patient 1, while there was no significant change in rFLC seen in Patient 2. This is in accordance with the findings of our published study ${ }^{[6,7]}$.

Beta 2 microglobulin, lactate dehydrogenase, calcium, albumin, haemoglobin, creatinine, and PTH remained stable in both patients during the 2 year treatment period.

Leucocyte surface antigen markers (T cell markers CD3, CD4 and CD8) and immunoglobulin levels (IgA and IgM) were monitored over the 2 year period in order to determine the long term effects of curcumin on immune function.

Patient 1 showed a 22\% decrease in CD3 T cells and a 37\% decrease in CD4 T helper cells over 2 years. This patient had hypogammaglobulinemia at baseline (decreased $\operatorname{IgA}$ and $\operatorname{IgM}$ ) and demonstrated stable $\operatorname{IgA}$ and $\operatorname{IgM}$ levels over the 2 year 
treatment period (see Table 1). Patient 2 showed a slight increase or no change in T cell markers. This patient had normal baseline levels of IgA and IgM. There was a slight decrease in IgM and an increase in IgA after the 2 year treatment period.

Figure 2a. Immunoperoxidase stain of CD138 plasma cells in bone marrow of Patient 2 at baseline $(7 \%)$

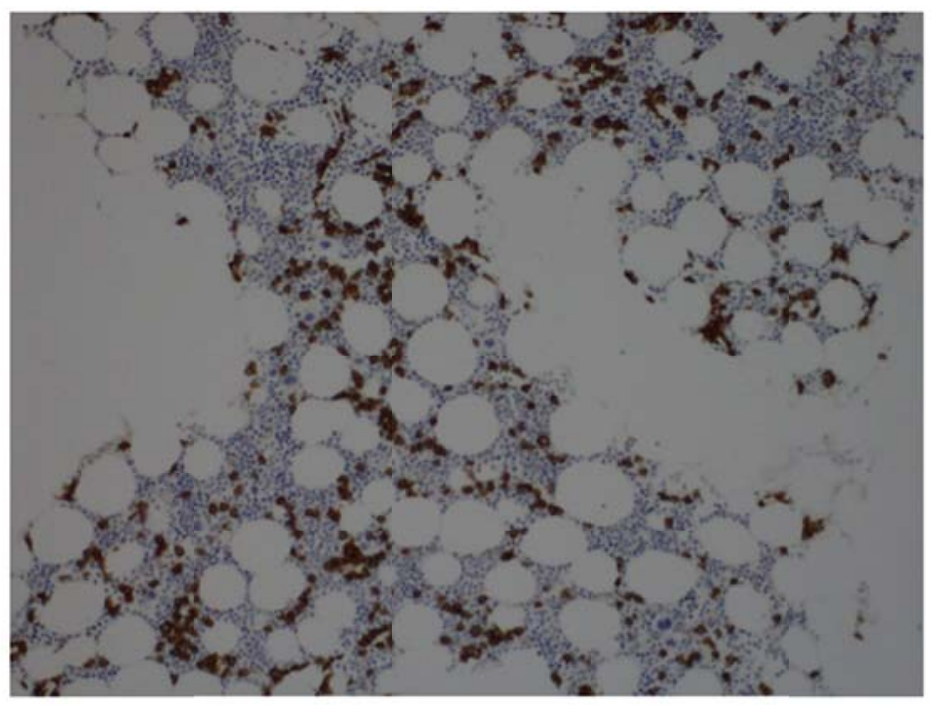

Figure 2b. Immunoperoxidase stain of CD138 plasma cells in bone marrow of Patient 2 after 2 years of curcumin therapy $(2 \%)$

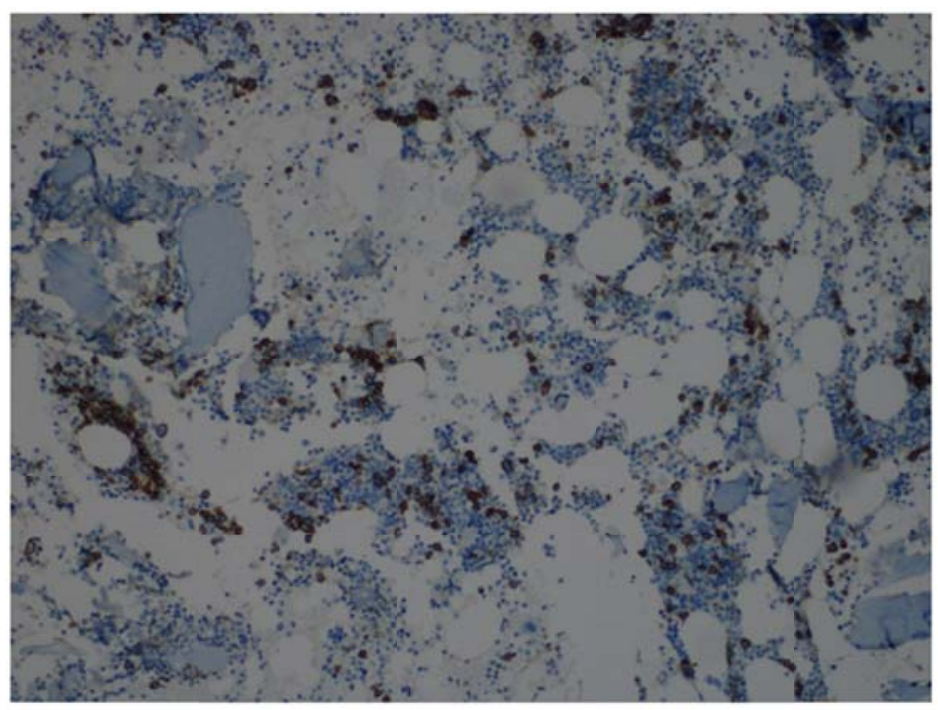

Table 2. T cell (\%), IgA and IgM immunoglobulin levels of $18 \mathrm{IgG}$ plasma cell dyscrasia patients from previous randomised study at baseline and after 9 months of curcumin therapy (6months $4 \mathrm{~g}$ and 3 months $8 \mathrm{~g}$ )

\begin{tabular}{llll}
\hline & At baseline & At 9 months & P value \\
\hline CD3 T cell (\%) & $77.9+8.3$ & $78.2+9.8$ & 0.8 \\
CD4 T helper cell (\%) & $46.5+8.9$ & $46.7+8.8$ & 0.9 \\
CD8 Cytotoxic T cell (\%) & $27.9+9.6$ & $27.4+12.3$ & 0.7 \\
IgA $(0.6-3.96 \mathrm{~g} / \mathrm{L})$ & $0.67+0.5$ & $0.64+0.48$ & 0.5 \\
$\operatorname{IgM}(0.48-3.04 \mathrm{~g} / \mathrm{L})$ & $0.53+0.43$ & $0.47+0.37$ & 0.04 \\
$\operatorname{IgG}(6.2-14.4 \mathrm{~g} / \mathrm{L})$ & $30+9.4$ & $29.25+7.94$ & 0.34 \\
\hline
\end{tabular}


To further determine the effect of curcumin on immune function, we re-looked at and analysed the data from our previous randomised study ${ }^{[6]}$. Eighteen (of 25) patients completed the 9 month study (ie 6 months of $4 \mathrm{~g}$ and 3 months of $8 \mathrm{~g}$ curcumin). All 18 patients had IgG plasma cell dyscrasias. Analysis of surface leucocyte antigen characterisation and immunoglobulin level data from baseline till 9 months showed that in 18 patients there was no mean change in percentage distribution of CD3 T cells, CD4 T helper cells and CD8 cytotoxic T cells (see Table 2) over 9 months of curcumin therapy. There was no change in $\operatorname{IgA}$, however, there was a decrease in $\operatorname{IgM}(\mathrm{P}=0.04)$ from baseline till 9 months (see Table 2).

\section{Discussion}

We describe the effects of 2-years of curcumin therapy on two SMM patients, one of these (ie patient 1) at high risk of transformation to multiple myeloma. Both these patients showed a continued improvement in several markers of their disease activity and in particular, a decrease in \% plasma cells in the bone marrow. These data are in accordance with our previous findings ${ }^{[5,6]}$. Although myeloma is a "patchy" disease, the bone histopathology failed to demonstrate progression of the disease, but suggested an improvement in the plasma cell infiltrate.

The mechanism(s) by which curcumin slows down the disease activity in plasma cell dyscrasias is unclear. Previous studies have identified down-regulation of interleukin-6 (a growth factor for myeloma and also an inflammatory cytokine) and suppression of receptor activator of nuclear factor kappa-B ligand (RANKL) signaling as two possibilities ${ }^{[2-4,8]}$. In their recent review ${ }^{[9]}$, Vermorken et al have attributed the beneficial effect of curcumin to its potential anti-inflammatory action. They also expressed concerns about the possible immunosuppressive effects of curcumin and its effects on cellular immunity. Our experience to date does not substantiate these concerns. A detailed analysis of immune function in 18 patients who had previously been studied and treated with curcumin for 9 months (see Table 2) did not show significant changes in the number of T-cell (CD3, CD4 and CD8) subsets. These findings can now be extended to 2 years as shown in Patients 1 and 2. Neither of these patients had any clinical events attributable to immunosuppression (infections, progression to myeloma or development of a second malignancy). Furthermore, neither patient displayed any side-effects from long term, high dose curcumin therapy and neither has developed skeletal events that require bisphosphanate therapy.

Our results are encouraging, but the exact role and place of curcumin for patients with monoclonal gammopathies and SMM will need to be determined by large scale, multi-centre studies.

\section{References}

[1] Kyle RA, Buadi F, Rajkumar SV. Management of monoclonal gammopathy of undetermined significance (MGUS) and smoldering multiple myeloma (SMM). Oncology (Williston Park). 2011; 25(7):578-86. PMid:21888255

[2] Aggarwal BB, Kumar K, Aggarwal MS, Shishodia S. Curcumin derived from turmeric (Curcuma longa): a spice for all seasons. In: Bagchi D, Preuss HG, editors. Phytopharmaceuticals in cancer chemoprevention. Boca Raton: CRC Press; 2004: $349-87$. PMid:15123863 http://dx.doi.org/10.1201/9780203506707.ch23

[3] Bharti AC, Donato N, Singh S, Aggarwal BB. Curcumin (Diferuloylmethane) down-regulates the constitutive activation of nuclear factor ${ }_{-} \mathrm{B}$ and $\mathrm{I}_{\mathrm{K}} \mathrm{B} \alpha$ kinase in human multiple myeloma cells, leading to suppression of proliferation and induction of apoptosis. Blood. 2003; 101:1053-1062.

PMid:12393461 http://dx.doi.org/10.1182/blood-2002-05-1320

[4] Vadhan-Raj S, Weber DM, Wang M, et al. Curcumin Downregulates NF-KB and Related Genes in Patients with Multiple Myeloma: Results of a Phase 1/11 Study. Blood. 2007; 110:1177 .

[5] Golombick T, Diamond T, Badmaev V, et al. The Potential Role of Curcumin in Patients with Monoclonal Gammopathy of Undefined Significance - Its Effect on Paraproteinemia and The Urinary N-Telopeptide of Type 1 Collagen Bone Turnover Marker. Clin Cancer Res. 2009; 15(18):5917-5922.

PMid:19737963 http://dx.doi.org/10.1158/1078-0432.CCR-08-2217 
[6] Golombick T, Diamond T, Manoharan A, Ramakrishna R. Monoclonal Gammopathy of Undetermined Significance (MGUS), Smoldering Multiple Myeloma (SMM) and Curcumin: A Randomised, Double-blind Placebo-Controlled Cross-over 4g study and an Open-label 8g Extension Study. American J Hematology. 2012; 87: 455-460.

PMid:22473809 http://dx.doi.org/10.1002/ajh.23159

[7] Golombick T, Diamond T, Manoharan A and Ramakrishna R. Response to Vermorken et al - curcumin and free light chains.Am J Hematol. 2012; 87:E80-E81. http://dx.doi.org/10.1002/ajh.23294

[8] Oh S, Kyung TW, Choi HS. Curcumin inhibits osteoclastogenesis by decreasing receptor activator of nuclear factor-kappa B ligand (RANKL) in bone marrow stromal cells. Molecules and Cells. 2008; 26(5):486-9. PMid:18719352

[9] Vermorken AJM, Zhu J, Van de Ven WJM, Andres E. Curcumin for monoclonal gammopathies. What can we hope for, what should we fear? Critical Reviews in Oncology/Hematology. 2012. http://dx.doi.org/10.1016/j.critrevonc.2012.04.005 